picture of Non-Fiction Theatre as well as Jo Fisher for letting me reproduce the poster of her 2016 play And Then You Kissed Me: thank you! There are also many scholars - too many to mention individually here - in Europe, America and Asia who have helped in more subtle, but meaningful ways.

During the final part of this lengthy process, I am very grateful as well for the understanding of my former colleagues at Eton College between 2014 and 2016.

Finally, I would most of all like to thank my family for their continuous support over the years and in particular my brother Gilles Garson for helping me on the technical front at the eleventh hour. Thanks to all my friends and colleagues who were there from the beginning and stayed the distance, those who are here at the end: Sarah Ablett, Charlotte Agnew, Rosemary Agnew, Vanessa Barbaro, Johanna Bielher, Maria Elena Capitani, Emilie Chehilita, simon David, Johanne Keiding, Charlotte Lamailloux, Lucile Lesage, Framboise Ollivier, Hana Pavelková, Laurence Pons-Wood, Laure Porta, Domi Pritchard, Dominique and Huguette Py, Ellen Redling, Eleanor Rodda, Verónica Rodríguez, Haroon Shirwani, Jan Suk, Clare Summerskill and Agathe Torti-Alcayaga.

\title{
Copyright Acknowledgements
}

Earlier versions of material used in Chapters 3.2, 3.3 and 4.2 appeared in the following articles, reprinted with permission from the publishers:

Garson, Cyrielle. "Remixing Politics: The Case of Headphone-Verbatim Theatre in Britain." Journal of Contemporary Drama in English, vol. 2, no. 1, 2014, pp. 50-62.

Garson, Cyrielle. "Does Verbatim Theatre Still Talk the Nation Talk?.” Journal of Contemporary Drama in English, vol. 6, no. 1, 2018, pp. 206-19.

Garson, Cyrielle. "Playing the Truth Game 'Verbatim' : from Tribunal Plays to Experimental Crime Plays on the Contemporary British Stage." Coup de Théâtre, vol. 32, 2018, pp. 157-79. 